\title{
Output Power Stability for Wind Turbine by using two Fault Detection Technique and PID - Fuzzy Controller in the Doubly fed Induction Generator
}

\author{
Ajay Kumar Shukla, Anil Kumar Kurchania
}

\begin{abstract}
The generation of electricity through a wind turbine system is rapidly increasing. Generation of an electricity form a wind turbine is one of the preeminent renewables sources of energy as it is easily available. In many wind farms, the speed of wind is variable due to which achieving stable power output and fault detection is one of the challenges. This objective can be achieved by a doubly fed induction generator (DFIG) along with the use of a fuzzy -PID controller and two fault detection technique in WTs. This Paper shows an investigation of the fault's detection and improvement in the DFIG model for the constant/stable power output. This model design to show DFIG $9 M W(6 \times 1.5)$ along with a $30 \mathrm{~km}$ transmission line and the Frequency used for RLC specification is $60 \mathrm{~Hz}$. Asynchronous machine in plant of $1.68 \mathrm{MW}, 0.93$ power factor, and $2300 \mathrm{~V}$ line voltage with mechanical power $3 \times 10^{3} \mathrm{~W}$. The initial constant wind speed of $15 \mathrm{~ms}^{-1}$ is maintained. Two fault detectors, one phase fault at B25 (25 kV) before the transmission to three-phase two winding transformer. Other phase faults at B120 (120 kV) before the transmission to three phase mutual inductance. The fault actuator in the doubly fed induction generators are reliable and also maintains the safety of wind turbine connected with a grid. PID-Fuzzy Controller is introduced to regulate the speed of the rotor by adjusting pitch which controls speed changes. The result shows due to controlling of pitch angle output level is improved and a good quality factor is achieved. We have introduced a fuzzy controller so the maximum output power can be established to the grid at the trip. In this research work, mathematical modeling of DFIG is presented.
\end{abstract}

Keywords: Doubly fed induction generator (DFIG), Fuzzy logic controller, Fault detection, Fault Diagnosis, stable output power.

\section{INTRODUCTION}

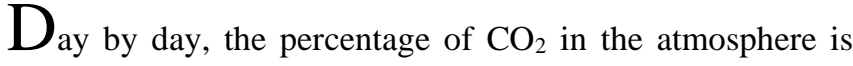
therefore many countries are emphasising the move towards the usage of renewable energy sources. Wind energy is a source that is easily available, with changing generation different types of wind turbine generators (WTG) were invented, but due to changing environmental conditions, it is very difficult to generate constant output power.

Manuscript received on August 14, 2021.

Revised Manuscript received on September 13, 2021.

Manuscript published on October 30, 2021.

* Correspondence Author

Ajay Kumar Shukla*, P.hD Scholar, Department of Electrical and Electronic Engineering Rabindranath Tagore University, Bhopal, (M.P.) India.

Anil Kumar Kurchania, Supervisor, Department of Electrical and Electronics Engineering Rabindranath Tagore University, Bhopal, (M.P.) India.

(C) The Authors. Published by Blue Eyes Intelligence Engineering and Sciences Publication (BEIESP). This is an open access article under the CC BY-NC-ND license (http://creativecommons.org/licenses/by-nc-nd/4.0/)

This paper mainly highlights the stability of output power in DFIG connected with grid and $30 \mathrm{~km}$ transmission line and fault detection in a transmission line to get more stable and smooth output power with the least fluctuation. The safety and reliability of DFIG are very important, therefore the fault diagnosis of the DFIG machine is very essential to improve power quality, to reduce a maintenance cost and minimize the downtime of the machines. The possible faults occurred in Doubly fed induction generators are speed sensor fault, current senser fault and voltage senser faults. These faults in a senser affect the overall performance of generator, affect the regularity in transmission of an electricity and there is high probability of damage to generator [1] The DFIG generates electricity under different faults which arises due to generator G1 loss of excitation, 3 phase to ground fault, 3 phase to phase fault and signal line to ground fault. These all losses are detected to analyse the transient response and to maintain stability in output power. The output power from a grid will quickly fluctuate, as the grid is connected directly therefore the impact due to the faults will easily affect the overall performance of the turbine system. [2] Due to the faults that emerge in the system as mentioned above. The reactive power produced from the turbine increases, as at the point of common coupling the phase voltage drops suddenly, so it is important to eliminate the faults from the stator and rotor for stable output power from the DFIG. Now looking into the facts, it is the prime task to isolate the faults which are detected in the rotor and stator, meanwhile, The improved current observer detects both hard and soft faults that occurred in the current sensor. The analysis of voltage-current sensor faults in the stator and fault identification of self excited induction generator are the key for the improvement therefore to identify faults an algorithm has been designed. Detailed research was performed, including some visits to wind farms to design a perfect MATLAB modeling of DFIG for controllability and stability of the output power can be extracted from the wind turbine[3].

\section{DESCRIPTION AND MODELING OF DFIG-BASED WIND TURBINE}

DFIG is a wound rotor induction generator where a generator is connected to the power grid via rotor side and grid side converter. When rotor and stator have different magnetic flux going on the opposite side at the same time to each other can induce a faster speed on the rotor.

Published By:

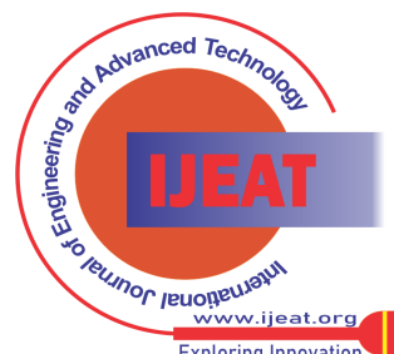




\section{Output Power Stability for Wind Turbine by using two Fault Detection Technique and PID - Fuzzy Controller in the Doubly fed Induction Generator}

Rotor terminal can be accessible in the wound rotor machine, where the rotor winding is identical to the stator winding. 3-phase windings are available on the rotor side and stator side. The rotor is connected to the slip ring, so output voltage can be extracted from the terminals.

The advantage of these machines is that the power can be taken out from the rotor and stator and transferred through a grid. A doubly fed induction generator provides better control on the speed. It responds very quickly to change in the wind speed, and it is intelligent to control the line current is some extent, also day by day more new research is taking place, so the controllability and stability can be improved. The best thing we can find in the DFIG generator is the power electronics converter present in DFIG which controls the rotor circuit. In case of low voltage, the generator will manage to import and export reactive power and support the transmission grid. In the past, authors have proposed different ways for fault detection. To detect the faults and for reconfiguring the signal of a current sensor for a DFIG, they had proposed a bilinear observer which also provides residuals, here residuals detect the current sensor faults. Other researchers have concentrated their studies to control the reconfiguration of current signals and current sensor FDI. To produce residuals for detecting current sensor faults, some of the authors used in-parallel techniques. To isolate the identified faults in the rotor and stator, an algorithm was proposed so the fault can be detected. The authors have proposed the different complex techniques to detect the faults, but then also perfectly stable and controlled output was not achieved.. In this proposed paper, the fault detection and resolution approach was implemented to diagnose the current sensor fault in the transmission line of the doubly fed induction generator. To diagnose and send the feedback signal to the controllers of the generator an algorithm is designed and also code programming was developed for the fuzzy logic controller. The fuzzy model is connected with a feedback link, so it can adjust the pitch angle. The wind turbine blade will be in the link of wind attack and maximum power can be extracted, a mathematical logic algorithms were developed to input data in the fuzzy controller and the fault has been detected, it also clearly reflects from the smooth output voltage and power generated by a wind turbine. Based on the detected faults, the signal goes to the pitch controller to adjust a blade angle so the developed fault will not escalate further to cause any kind of damage to the system. Also after the detected fault, it is found that the generated power is less than expected, the wind blades come at a maximum attacking angle with the help of a pitch controller and if the generated power is more than expected then the wind blades come at a less attacking angle. These all decisions are based on the feedback signals provided to the fuzzy PID controller so the pitch angle can be controlled accordingly and the production of constant and stable output power can be achieved.

\section{MODELING AND CONTROLLING OF DFIG-BASED WIND TURBINE}

According to Betz Law, the maximum 59.3\% of available wind power can be extracted by the wind turbine to produce an electricity The doesn't mean that efficiency of wind turbine is $59.3 \%$, there also be a different loss such as components.

The wind power extracted $(\mathrm{Pa})$ by wind turbine blade is expressed as [4]

$P_{a}=C_{p}(\lambda, \beta) P_{w}=\frac{1}{2} \rho \pi R^{2} C_{p}(\lambda, \beta) v^{3}$

Were,

$C_{p}(\lambda, \beta)$ - aerodynamic efficiency, $\beta$ - Pitch angle, $\lambda$ - tip speed ratio, $\rho$ - density of the air, $\mathrm{R}$ - Radius of blade connect to a rotor, $\mathrm{v}$ - Speed of wind.

The $(\lambda)$, the tip speed ratio is defined as -

$\lambda=\frac{\text { linear velocity of the blade tip }\left(\Omega_{R}\right)}{\text { wind speed }(v)}$

Here $\Omega$ - angular speed of a rotor and $\mathrm{v}$ - speed of wind hitting the turbine blade.

\section{IV.ELECTRICAL MODEL OF DFIG}

The doubly fed induction generator is a wound rotor induction machine work on synchronous mode.

The electrical modeling equation is demonstrated as [5] -

$V_{d s}=R_{s} i_{d s}+\frac{d \phi_{d s}}{d t}-w_{s} \phi_{q s}$

$V_{q s}=R_{s} i_{q s}+\frac{d \phi_{q s}}{d t}+w_{s} \phi_{d s}$

$V_{d r}=R_{r} i_{d r}+\frac{d \phi_{d r}}{d t}-w_{s} \phi_{q r}$

$V_{q r}=R_{s} i_{q r}+\frac{d \phi_{q r}}{d t}+w_{s} \phi_{d r}$

with

$\phi_{d s}=X_{s} i_{d s}+X_{m} i_{d r}$

$\phi_{q s}=X_{s} i_{q s}+X_{m} i_{q r}$

$\phi_{d r}=X_{r} i_{d r}+X_{m} i_{d s}$

$\phi_{q r}=X_{r} i_{q r}+X_{m} i_{q s}$

Where $\mathrm{V}$ represents a voltage (Volt), i represents a currents (Ampere), R represents a resistance $(\Omega), \phi$ represents a flux linkage (Weber). Here $X_{r}$ - rotor inductance, $X_{s}$ - stato inductance and $X_{m}$ - magnetization inductance.

The superscripts $\mathrm{q}$ and $\mathrm{q}$ mentioned in the above equations means the direct and quadrature axis components. $\mathrm{r}$ and $\mathrm{s}$ means rotor and stator quantities, $w_{r}$ and $w_{s}$ are the rotor speed and stator speed of the generator respectively

The relation the electromagnetic torque for number of poles $(\mathrm{P})$, rotor angular velocity $\left(w_{r}\right)$ and stator angular velocity $\left(w_{s}\right)$ are shown by

$w_{r}=w_{s}-P \Omega_{m}$

$T_{e m}=\frac{P X_{m}}{L_{s}}\left(\phi_{q s} i_{d r}-\phi_{d s} i_{q r}\right)$

The wind turbine blades captures wind energy as the wind hits it, due to which a mechanical energy is transferred to rotor and torque is acting on the rotor $\left(\tau_{r}\right)$ is represented as$\tau_{r}(t)=\frac{\rho \pi R^{3} C_{q}[\lambda(t), \beta(t)] v_{w}^{2}(t)}{2}$

Here in the above equation torque action on the rotor $\tau_{r}$ is proportional to square of wind speed.

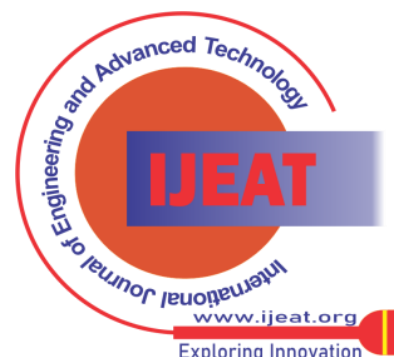




\section{METHODOLOGY}

The DFIG 9MW wind turbine is detailed in the MATLAB Simulink by using the simulation tool. Whilst the focus of this research work is to study the output power produced by the turbine and implementing the strategies to get stable output power by using two fault detection techniques and PID - Fuzzy controller. In this proposed model two fault detectors are used in-between $30 \mathrm{~km}$ of a transmission line. One fault detector is used at $10 \mathrm{~km}$ and the second detector at $20 \mathrm{~km}$ of a transmission line. To receive stable output power with maximum extraction, it is extremely important to identify the occurred error and rectify it. First, the fault that occurred in the system affect the drive train of the wind turbine. It can be observed if there is a slow change in friction coefficient with respect to time and due to sensor fault, the pitch angle $\beta$ provides an unconstrained measurement therefore the fault diagnosis strategies are implemented so the stable controlled output power can be extracted from a wind turbine. Also, the programmed signal fuzzy - PID controller is introduced in the simulation model with Mamdani type fuzzy logic control which controls the generator speed and reactive- active power of DFIG. This technique establishes the fidelity and robustness of control and the fuzzy direct speed control is quick, responsive and more effective than the indirect method of speed control. The Mandani type triangular membership function is created in the programmed FIS file and input values of current and voltage of each phase in inserted in the FIS file. The range of this membership function is kept as high, medium and low. The input value of zero sequence current and voltage is extracted by Sequence Analyzer. The output of these triangular membership functions is taken from the 'Tripsnew'. The phase base values of current and voltage are used. To detect the ground fault a zero-sequence component of current and voltage are considered for input in FIS. The number of rules is selected in the fuzzy system is based on faults and selected measurements described by the fuzzy model. IF and THEN operation is processed in a fuzzy inference system which connects the rules based on information acquired from the measured signal to diagnose its faults.

\section{RESULTS}

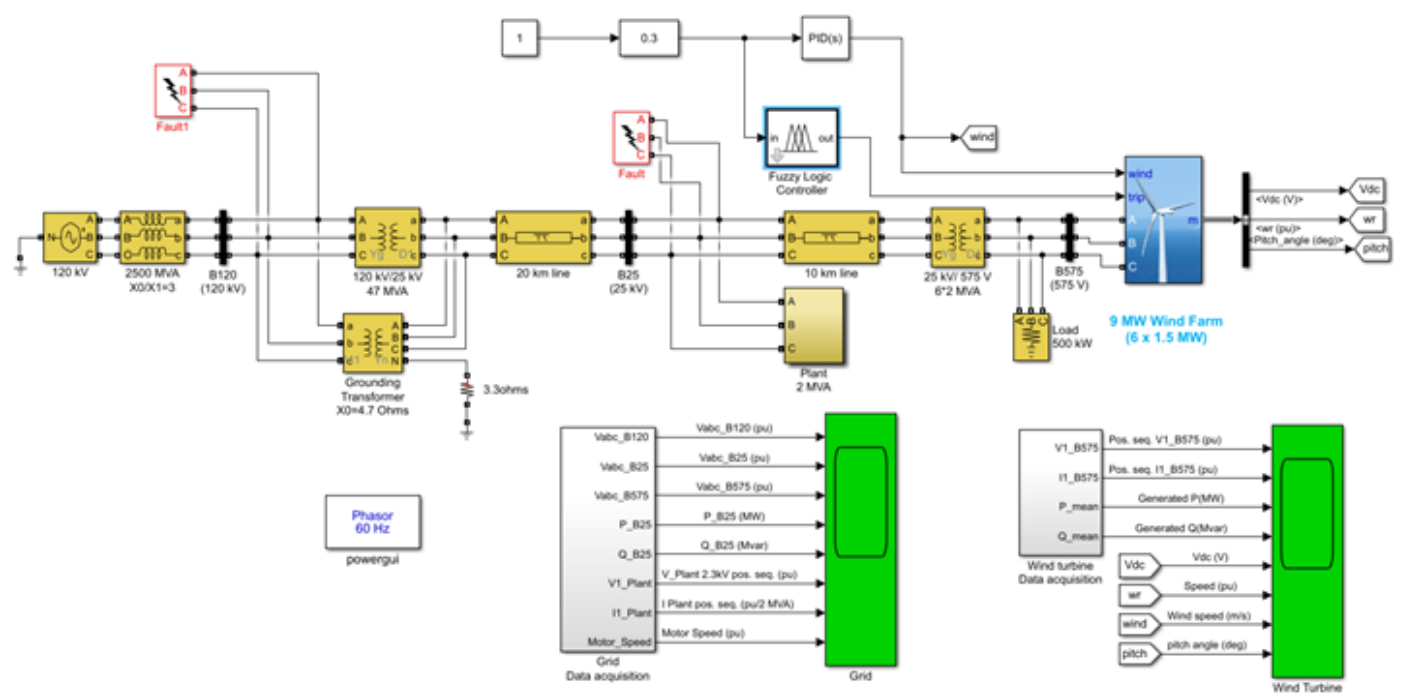

Figure 1: Detailed Proposed MATLAB Model

\section{Output responses:}

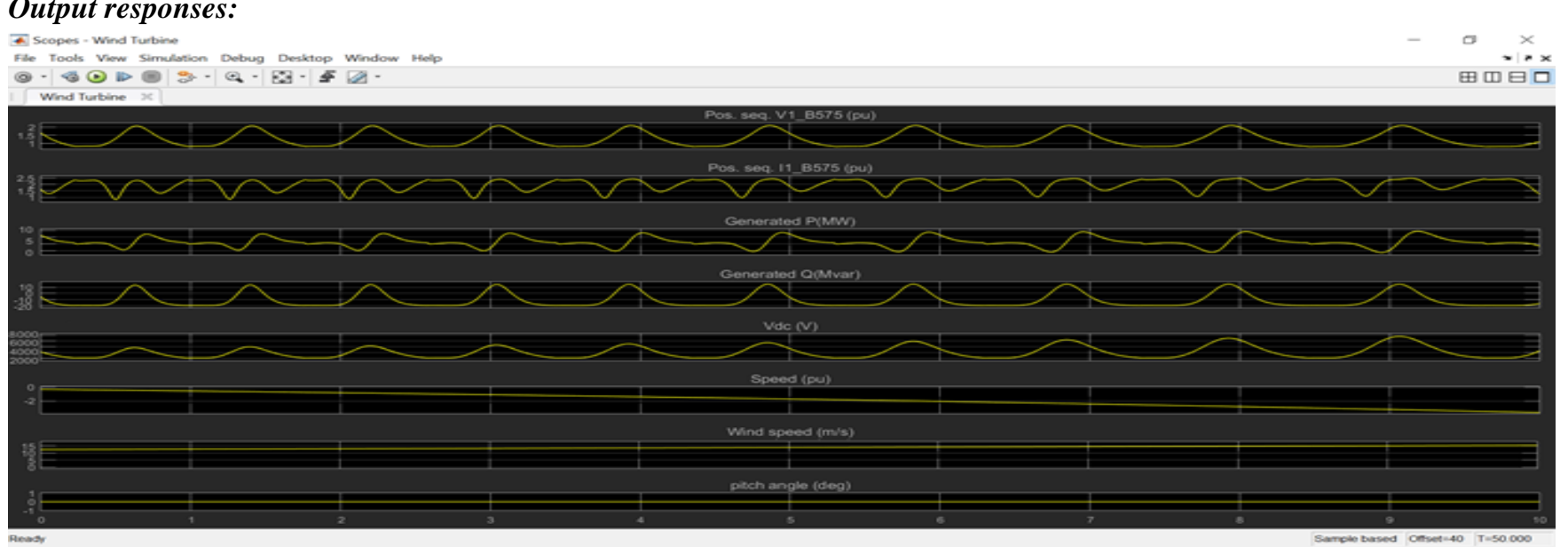

Figure 2: Wind Turbine Output Response DFIG

Published By:

Blue Eyes Intelligence Engineering

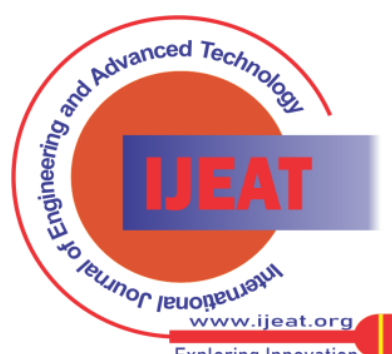

(C) Copyright: All rights reserved. $\quad$ Exploring Innovation 


\section{Output Power Stability for Wind Turbine by using two Fault Detection Technique and PID - Fuzzy Controller in the Doubly fed Induction Generator}

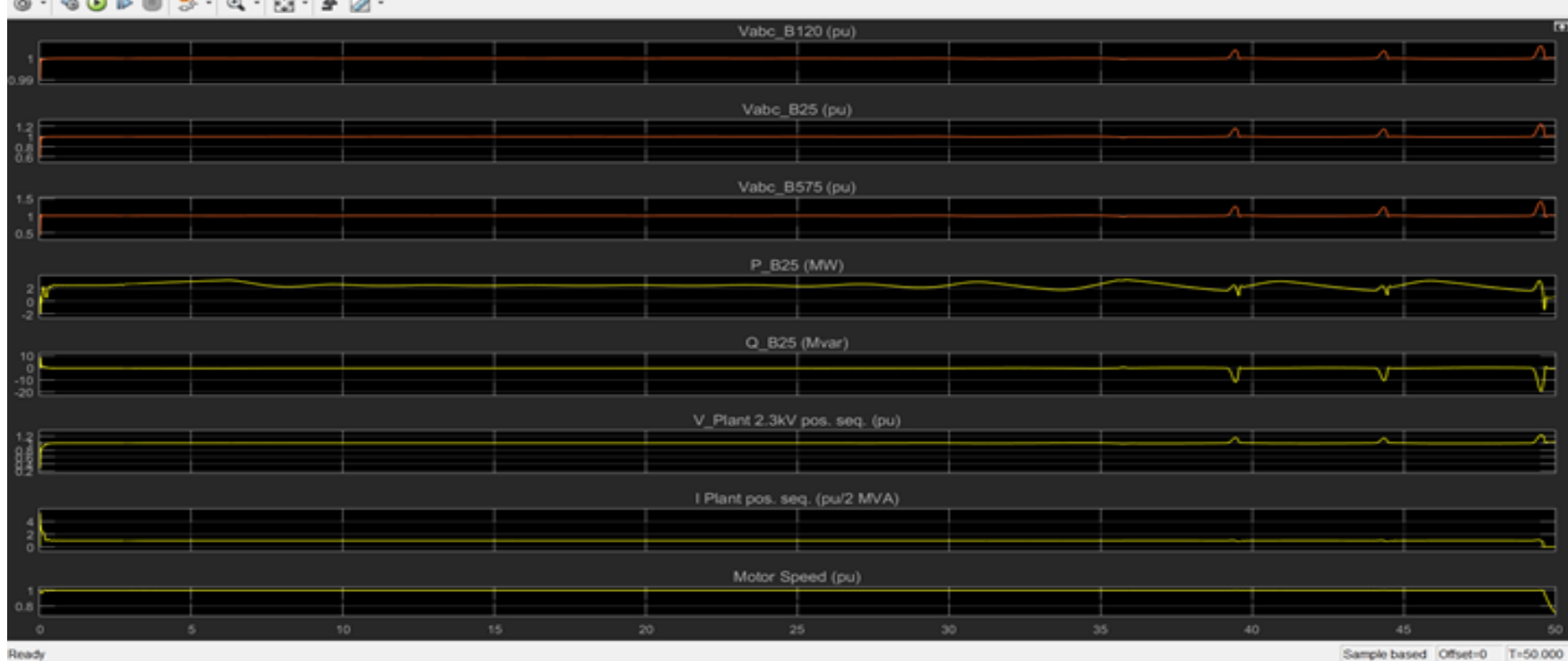

Figure 3: GRID output response for DFIG

\section{CONCLUSIONS}

In this paper, the study for the DFIG system is performed to get a stable output from the grid. The faults were identified and a signal direct to the fuzzy interference system to control the output power under the performance of fuzzyPID control. Also to avoid the aggravation of reactive power due to faults, the rotor speed, pitch angle along the stator power of DFIG is controlled. The diagnosed problems due to faults are solved with the help of FIS by designing the Mamdani type fuzzy logic control. The simulation results clearly show the steady-state response of output power. It indicates the perfect operation of the fuzzy - PID controllers along with two fault deductions in the transmission line.

The Electrical model of DFIG equations derived above in this paper is used in MATLAB, Simulink environment to design a DFIG model along with two fault detectors and a Fuzzy- PID controller. In the future, effective strategies can be used to reduce the relative power in the DFIG and to improve the grid distribution capabilities the fault ride can be improved. This research and construction of this model in Simulink show a stable, reliable, and robust performance of the DFIG under the effect of faults and fluctuations in reactive power produced in the wind turbine, the designed simulator has well-handled the uncertainties that occurred during the operation of production of the electricity.

\section{REFERENCE}

1. Rothenhagen, K., and F.w. Fuchs. "Current Sensor Fault Detection, Isolation, and Reconfiguration for Doubly Fed Induction Generators." IEEE Transactions on Industrial Electronics, vol. 56, no. 10, 2009, pp. 4239-4245., doi:10.1109/tie.2009.2017562.

2. Sathiyanarayanan, J. S., and A. Senthil Kumar. "Doubly Fed Induction Generator Wind Turbines with Fuzzy Controller: A Survey." The Scientific World Journal, vol. 2014, 2014, pp. 1-8., doi:10.1155/2014/252645.

3. Abdelmalek, S., Rezazi, S. and Azar, A., 2017. sensor faults detection and estimation for a dfig equipped wind turbine. Energy Procedia, 139, pp.3-9.

4. Jain, Pramod, 2010. Wind Energy Engineering, Second Edition. 2nd ed. McGraw-Hill Education.
5. Xu, L. and Wang, Y., 2007. Dynamic Modeling and Control of DFIGBased Wind Turbines Under Unbalanced Network Conditions. IEEE Transactions on Power Systems, 22(1), pp.314-323.

6. Simani, S. and Castaldi, P., 2019. Intelligent Fault Diagnosis Techniques Applied to an Offshore Wind Turbine System. Applied Sciences, 9(4), p.783.

\section{AUTHORS PROFILE}

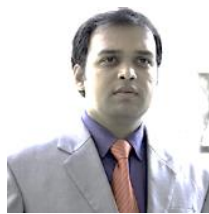

Ajay Kumar Shukla, P.hD Research Scholar, Department of Electrical and Electronic Engineering Rabindranath Tagore University, Bhopal, Madhya Pradesh, India.

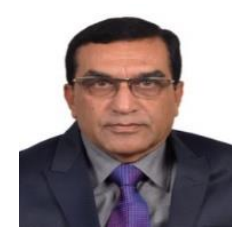

Dr. Anil Kumar Kurchania, Director, Centre for Renewable Energy, Rabindranath Tagore University, Bhopal, Madhya Pradesh, India.

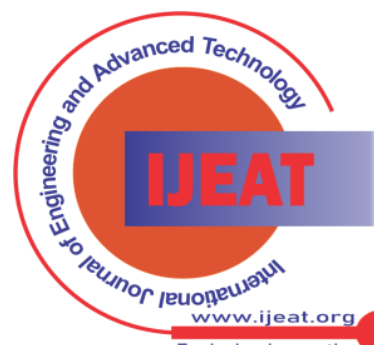

